\title{
ALL OVER THE WORLD WOMEN LIVE AND DIE IN PRISONS
}

For all women in crisis inside and outside the walls and especially and particularly to those who chose death over the hell that is "life" in prison, for the unresolved grief surrounding those who have died in prison, for their young lives taken by despair, for their deaths and those of others given no compensation or apology by any government, we can offer only their own words.

The prose and articles by Sandy (Sam) Sayer, Marie (Custard) Custer, Marlene (Shaggy) Moore and Pat (Patty) Bear stand together as a powerful Requiem.

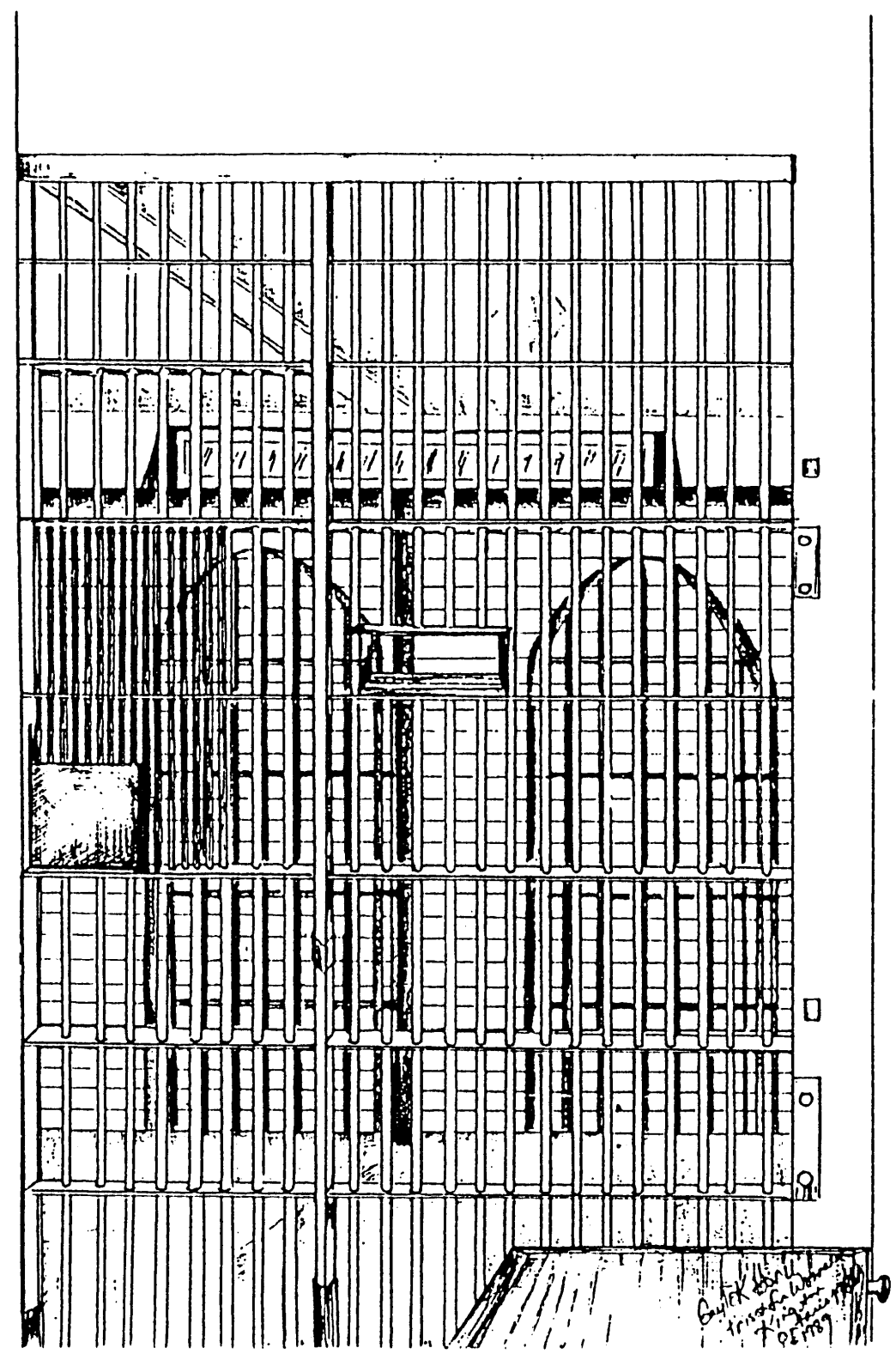

